\title{
Low Proline Diet in Type I Hyperprolinaemia
}

\author{
J. T. HARRIES, A. T. PIESOWICZ, ${ }^{\star}$ J. W. T. SEAKINS, D. E. M. FRANCIS, and O. H. WOLFF \\ From The Hospital for Sick Children, and the Institute of Child Health, University of London
}

\begin{abstract}
Harries, J. T., Piesowicz, A. T., Seakins, J. W. T., Francis, D. E. M., and Wolf, O. H. (1971). Archives of Disease in Childhood, 46, 72. Low proline diet in type I hyperprolinaemia. A diagnosis of Type I hyperprolinaemia was made in a 7-month-old infant who presented with hypocalcaemic convulsions and malabsorption. The plasma levels of proline were grossly raised and the urinary excretion of proline, hydroxyproline, and glycine was increased; neurological development was delayed and there were associated abnormalities of the electroencephalogram, renal tract, and bones. Restriction of dietary proline at the age of 9 months resulted in a prompt fall of plasma levels of proline to normal, and a low proline diet was continued until the age of 27 months when persistence of the biochemical defect was shown. During the period of dietary treatment, growth was satisfactory, mental development improved, and the electroencephalogram, and the renal, skeletal, and intestinal abnormalities disappeared. Proline should be regarded as a 'semi-essential' amino acid in the growing infant.
\end{abstract}

Hyperprolinaemia, appearing in several members of a family was first described by Scriver, Schafer, and Efron in 1961. Subsequently enzyme studies (Efron, 1965) showed two separate types (Fig. 1). Type $I$ is associated with proline oxidase deficiency and Type II with $\Delta^{\prime}$-pyrroline-5-carboxylic acid dehydrogenase (PC dehydrogenase) deficiency; both are characterized by raised blood proline levels and increased urinary excretion of proline, hydroxyproline, and glycine, but in Type II, urinary excretion of $\Delta^{\prime}$-pyrroline-5-carboxylic acid is also increased. Type I may be associated with mental retardation, renal abnormalities, hereditary deafness, and electroencephalographic abnormalities. Type II may be associated with mental retardation and seizures, but deafness and renal lesions have not been described.

Investigations in the experimental animal have shown that proline can be synthesized in the liver from the 'non-essential' amino acids glutamic acid and ornithine along the pathway indicated in Fig. 1. The enzymes necessary for its synthesis differ from those involved in its degradation (Meister, 1965); the quantitative importance of the synthetic pathway is not known. In the adult, short-term feeding experiments have shown that a positive nitrogen

Received 19 May 1970.

^Present address: Queen Mary's Hospital for Children, Carshalton, Surrey. balance can be maintained on a proline-free diet (Rose et al., 1955), and therefore the amino acid is generally regarded as 'non-essential'. This is probably the reason why no accounts have so far appeared describing the effects of a low proline diet in patients with Type I or Type II hyperprolinaemia, though Efron (1967) referred to 2 patients with Type II hyperprolinaemia who were receiving diets low in proline.

We report an infant in whom the diagnosis of Type I hyperprolinaemia was made at the age of 7 months. Dietary treatment resulted in prompt reduction of blood proline to normal levels. The

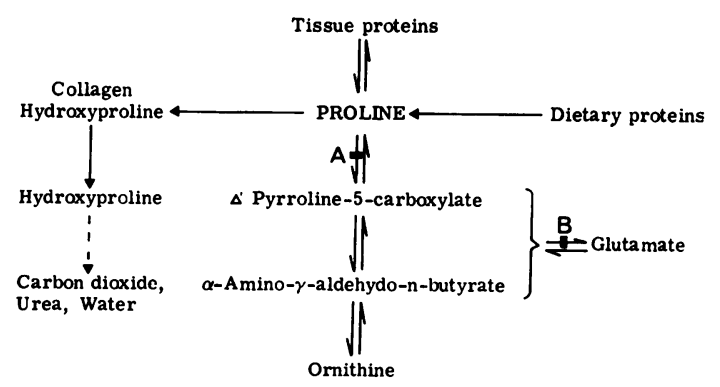

Fig. 1.-Metabolism of proline. (A) Defect in Type I hyperprolinaemia. (B) Defect in Type II hyperprolinaemia. Interconversion of $\Delta^{\prime}$ pyrroline-5-carboxylate and $a$-amino- $\gamma$-aldehydo-n-butyrate occurs spontaneously. 
patient was briefly reported at a meeting of the British Paediatric Association (Piesowicz, 1968).

\section{Case Report}

The patient, a boy, was born at term after a normal pregnancy and weighed $3.5 \mathrm{~kg}$; the mother's only previous pregnancy had ended in a spontaneous miscarriage at 3 months' gestation.

The parents are English and, though not known to be related, both their families had lived in Bedfordshire for several generations. The maternal grandmother suffered from hypertension and recurrent urinary tract infections; there was no other relevant family history. At the age of 2 weeks intermittent episodes of twitching of hands and feet occurred over a 2-day period. Thereafter progress was satisfactory until the age of 4 months when he developed diarrhoea and vomiting, severe apnoeic attacks, and convulsions. $\mathrm{He}$ was admitted in a collapsed state to the Luton General Hospital under the care of Dr. G. Fagg; investigations showed a plasma calcium level of $5.5 \mathrm{mg} / 100 \mathrm{ml}$; and the apnoeic attacks and convulsions responded to the administration of calcium. Despite the symptomatic improvement, low calcium levels persisted, and $x$-rays showed a fracture at the lower end of the right radius. Numerous investigations failed to elucidate the cause of the hypocalcaemia, and at the age of 6 months he was transferred to The Hospital for Sick Children, Great Ormond Street.

At this time his length was below the 3rd centile $(60 \mathrm{~cm})$, weight on the $3 \mathrm{rd}$ centile $(6.4 \mathrm{~kg})$, and skull circumference below the 10 th centile $(40 \mathrm{~cm})$. Physical examination was otherwise normal. Developmental quotient was assessed on the Griffiths Scale as 60 . Hearing was normal.

Hb was $9.6 \mathrm{~g} / 100 \mathrm{ml}$; white blood and platelet counts and blood coagulation tests were normal. Faecal fat estimated over a 5 -day period was $7 \cdot 2 \mathrm{~g} /$ day on an intake of $35 \mathrm{~g} /$ day. Peroral intestinal biopsy showed short and irregular villi with normal epithelium. Pancreatic enzymes, stool culture, sweat electrolytes, and barium meal and follow-through were normal; the faecal amino acid pattern was normal and faecal amino nitrogen was $32 \mathrm{mg} / 100 \mathrm{~g}$ (normal: 16-48); serum vitamin B12 was normal; serum folic acid $2 \cdot 0 \mathrm{~m} \mu \mathrm{g} / \mathrm{ml}$ (normal: $5 \cdot 9-21$ ); SGOT $148 \mathrm{p}$ moles pyruvate $/ 100 \mathrm{ml}$, SGPT $18 \mathrm{p}$ moles/ $100 \mathrm{ml}$; total serum bilirubin $<0.7 \mathrm{mg} / 100 \mathrm{ml}$. Plasma proteins normal; plasma calcium $6.5 \mathrm{mg} / 100 \mathrm{ml}$; plasma inorganic phosphorus $6.5 \mathrm{mg} / 100 \mathrm{ml}$; plasma alkaline phosphatase $29 \mathrm{KA}$ units $/ 100 \mathrm{ml}$; 24-hour urine $(350 \mathrm{ml})$, calcium and phosphorus 5.8 and $325 \mathrm{mg}$ respectivaly. PBI, growth hormone assay, urinary mucopolysaccharides, blood urea, plasma electrolytes, urine microscopy, and culture and creatinine clearance were normal; there was no significant proteinuria. An excretion pyelogram showed kidneys of normal size with normal calyces and pelves. Both ureters were dilated and tortuous with left ureteric striation (Fig. 2) due to reflux which was confirmed by cystogram. Skeletal $x$-rays showed areas of punctuate calcification in both feet (Fig. 3) and hips, and fractures of the distal ends of the radii. An EEG (Dr. Pampiglione) showed a diffuse abnormality with excess of irregular slow activity and of rhythmic fast activity over the posterior half of the head. Paroxysmal features appeared during photic stimulation suggesting an abnormal sensitivity to light. The findings were not typical of hypocalcaemia.

The plasma proline level was much raised and the urinary excretion of proline, hydroxyproline, and glycine was grossly increased (see section on amino acid studies). At this time feeds consisted almost entirely of cow's milk supplying $550 \mathrm{mg}$ proline/kg per day.

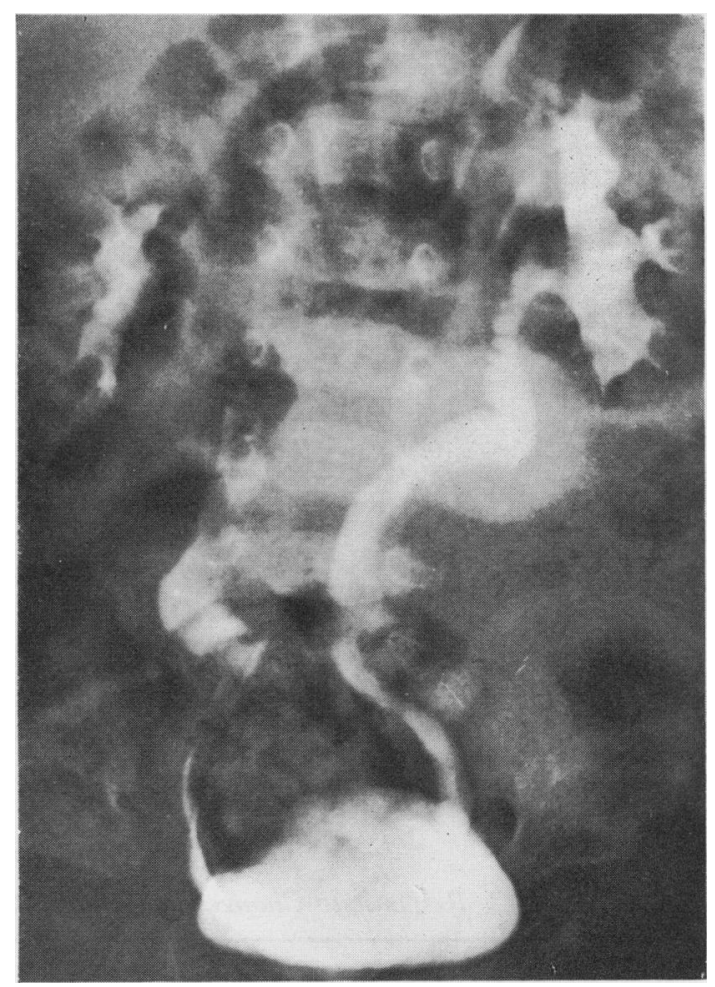

FIG. 2.-Excretion pyelogram age 7 months showing dilated and tortuous ureters with vesicoureteric reflux.

Initial treatment. Before starting a low proline diet, treatment with vitamin $\mathrm{D}(20,000$ i.u./day) and folic acid ( $5 \mathrm{mg}$ twice daily) resulted in some improvement in the patient's condition with a weight gain of $1.7 \mathrm{~kg}$, a return to normal of plasma calcium, inorganic phosphorus, and serum folic acid levels, and a reduction in faecal fat to $5.5 \mathrm{~g} /$ day on an intake of $35 \mathrm{~g} /$ day. Vitamin D and folic acid were continued in the same dose for approximately 10 weeks before dietary treatment was instituted and then maintained at a reduced dose of 400 i.u./day and $0.75 \mathrm{mg} /$ day, respectively. The initial improvement continued and weight gain accelerated after the dietary intake of proline was reduced at the age of 9 months. 
Dietary treatment and further progress. In order to assess the effect of dietary proline on plasma proline, the intake of proline was reduced to provide a virtually proline-free diet $(1.4 \mathrm{mg} / \mathrm{kg}$ per day); within 2 days plasma proline levels and the urinary amino acid pattern became normal. On this dietary regimen (see Appendix

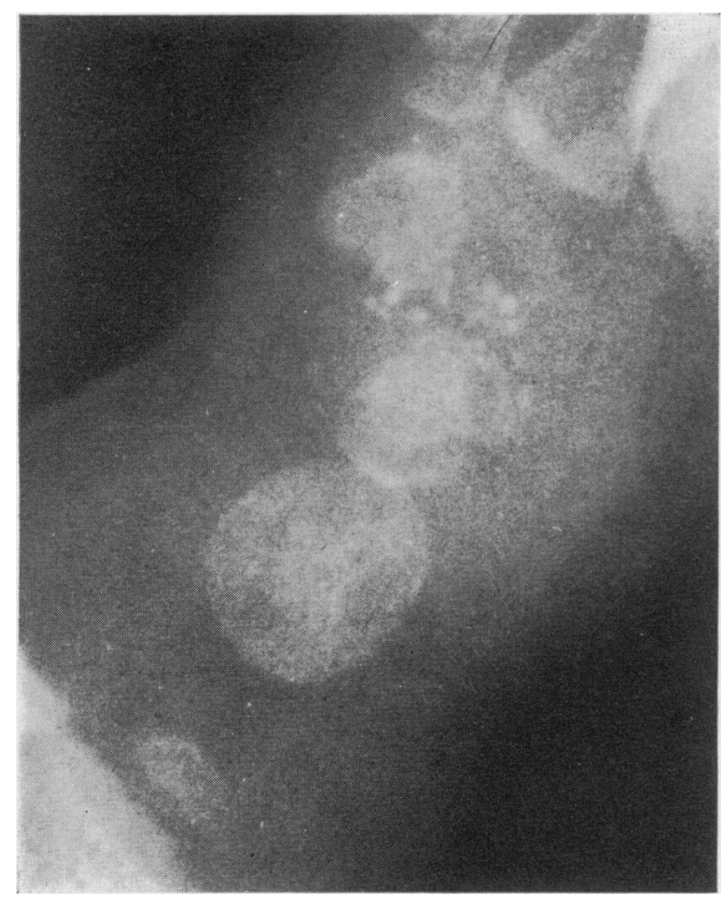

FIG. 3.-Punctuate calcification of left foot at 6 months.

I) weight gain was satisfactory, but after 4 weeks a raw, red, and scaling rash appeared on the buttocks and over the next few days spread to involve the trunk and face. Plasma proline levels estimated on two separate occasions at this time were 5 and $6 \mathrm{mg} / 100 \mathrm{ml}$. When the intake of proline was increased to $65 \mathrm{mg} / \mathrm{kg}$ per day, the rash rapidly cleared. The intake of proline was then slowly increased to that of a normal diet $(300 \mathrm{mg} / \mathrm{kg}$ per day), and the hyperprolinaemia (plasma proline $25 \mathrm{mg} / 100 \mathrm{ml}$ ) and characteristic aminoaciduria recurred. In view of this response and the possible causal relation between the high blood proline levels and the clinical abnormalities, the intake of proline was adjusted so as to maintain plasma levels between 8 and $10 \mathrm{mg} / 100 \mathrm{ml}$. The low proline diet has been continued until the present time (see Appendix I).

Weight gain increased from the 10th centile to above the 25th centile, but linear growth remained just below the 3rd centile (Fig. 4). Developmental quotient at 7 months was estimated to be 60 and at 2 years 75 ; during this time skull circumference increased from the 10th to the 20th centile. Serial EEG's showed normal maturation, and the abnormal responses to photic stimulation disappeared. Sequential studies of renal function remained normal. Intravenous pyelography was repeated 17 months after starting the diet (age 27 months) and showed the ureters to be of normal size and no vesico-ureteric reflux was seen in a cystogram. One month after dietary treatment was started faecal fat estimated over a 5-day period was $2.0 \mathrm{~g} /$ day on an intake of $34 \mathrm{~g} /$ day; the determination was repeated $3 \frac{1}{2}$ months later when faecal fat was $0.7 \mathrm{~g} /$ day on an intake of $35 \mathrm{~g} /$ day. The areas of punctuate calcification around the ossific centres for the calcaneum noted at the age of 6 months were less obvious at 11 months; at 24 months they had nearly disappeared (Fig. 5) and bone density had become normal.

TABLE I

Response to Changes in Dietary Proline: Age 27 months; Weight $12 \cdot 7 \mathrm{~kg}$

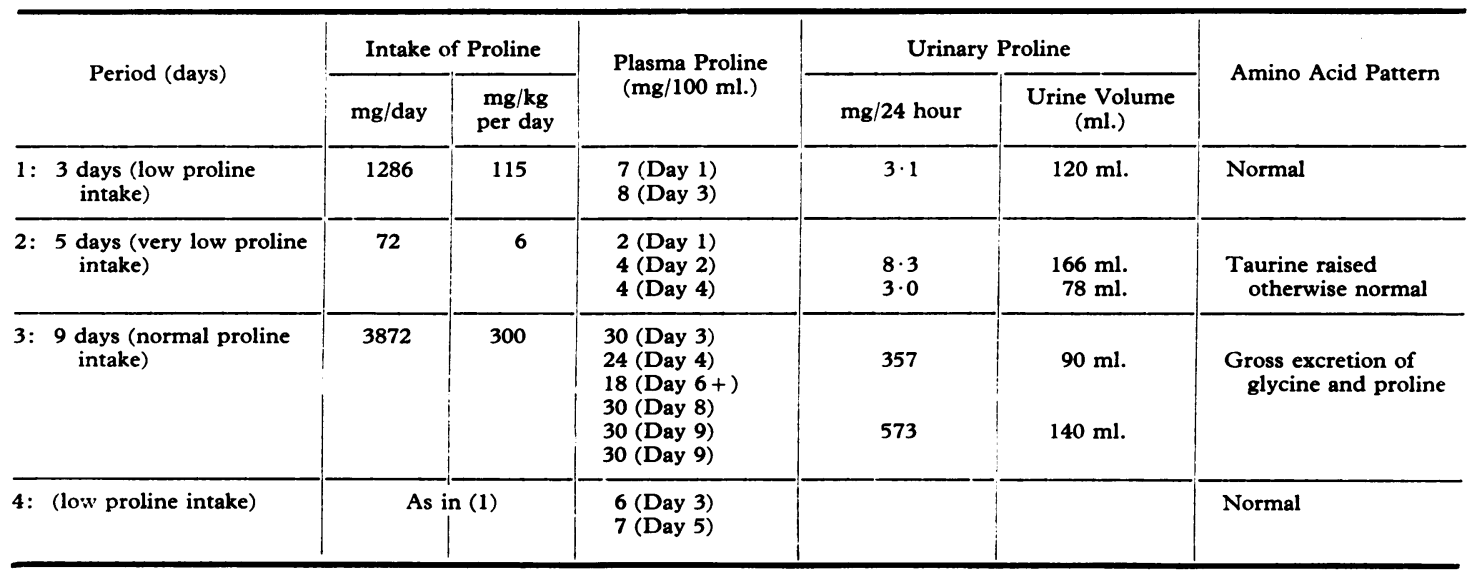

Calories: 1,290 (115/kg per day). Protein: $26.9 \mathrm{~g}(2 \cdot 1 \mathrm{~g} / \mathrm{kg}$ per day).

+ Vomited lunch and supper on previous day. 


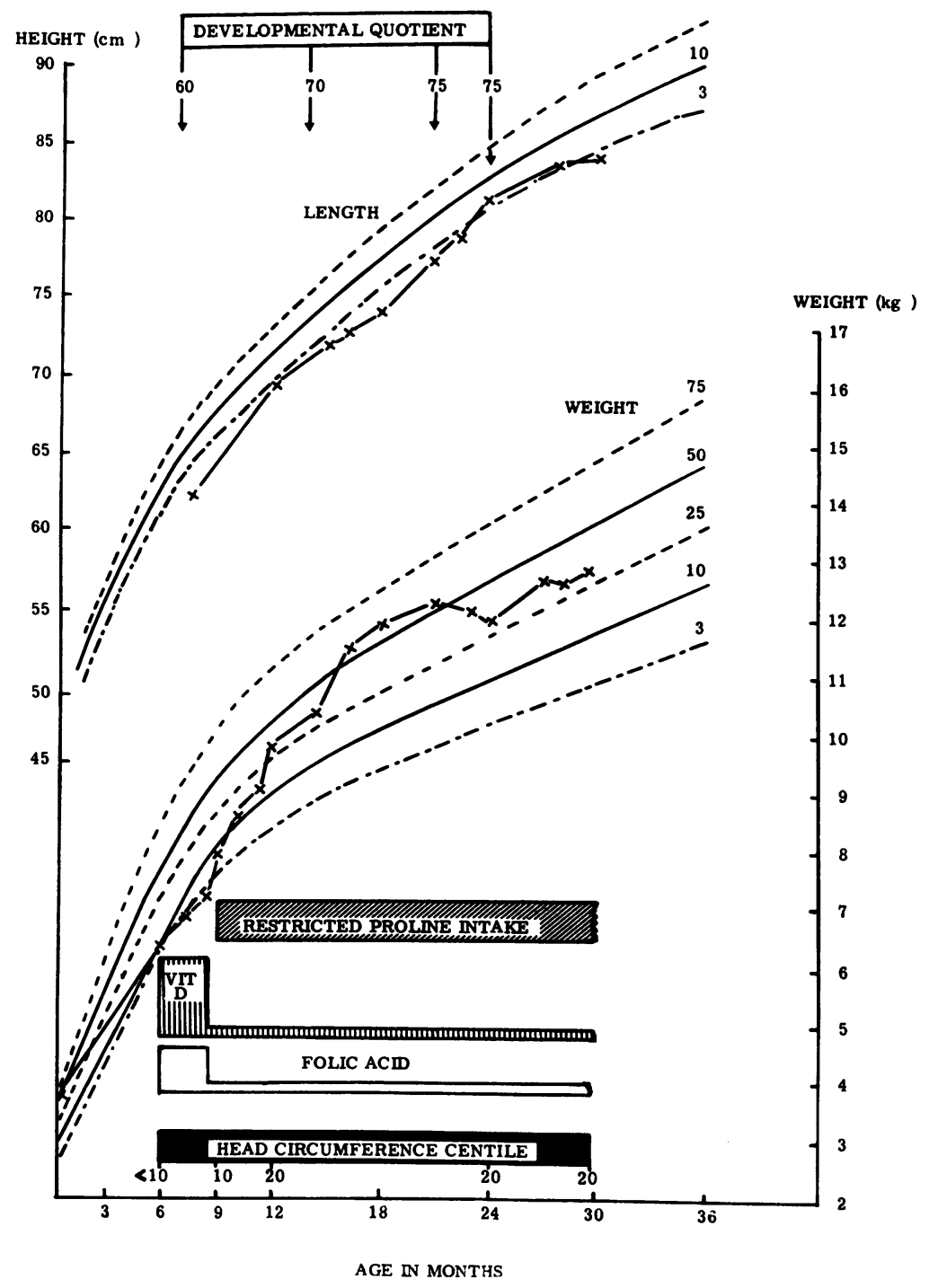

FIG. 4.-Growth and development.

Investigations of amino acid metabolism. The urinary amino acid pattern determined by high voltage electrophoresis at the age of 7 months showed a raised excretion of proline, hydroxyproline, and glycine (approximately 55, 15, and $170 \mathrm{mg} / 24$ hour, respectively). At this age proline and hydroxyproline are normally absent from urine.

The identity of these 3 amino acids was confirmed by specific colour reactions, paper chromatography, and electrophoresis. $\Delta$ 'pyrroline-5-carboxylic acid was not detected in urine while the patient was receiving a normal diet nor during a proline load test. Urinary sugars, phenolic acids, faecal amino acids were normal. Oneway paper chromatography of plasma showed a grossly raised concentration of proline $(30 \mathrm{mg} / 100 \mathrm{ml})$ which persisted while the patient ate a normal diet. At the age of 27 months, when the patient had been receiving the low proline diet ( $100-125 \mathrm{mg} / \mathrm{kg}$ per day) for approximately 17 months, detailed studies were repeated (Table I). The calorie and total protein content was kept constant during the 4 dietary periods. Dietary proline in periods 1 and 4 corresponded to that received during the previous year. In period 2 proline intake was reduced to negligible amounts by means of the proline- 
free amino acid mixture (Table II) which contains adequate amounts of glutamic acid; plasma proline levels promptly returned to normal. During period 3 a normal intake of proline was given and resulted in an immediate recurrence of the gross hyperprolinaemia and the aminoaciduria. Because of the persistence of the abnormality it was decided to continue the low proline diet.

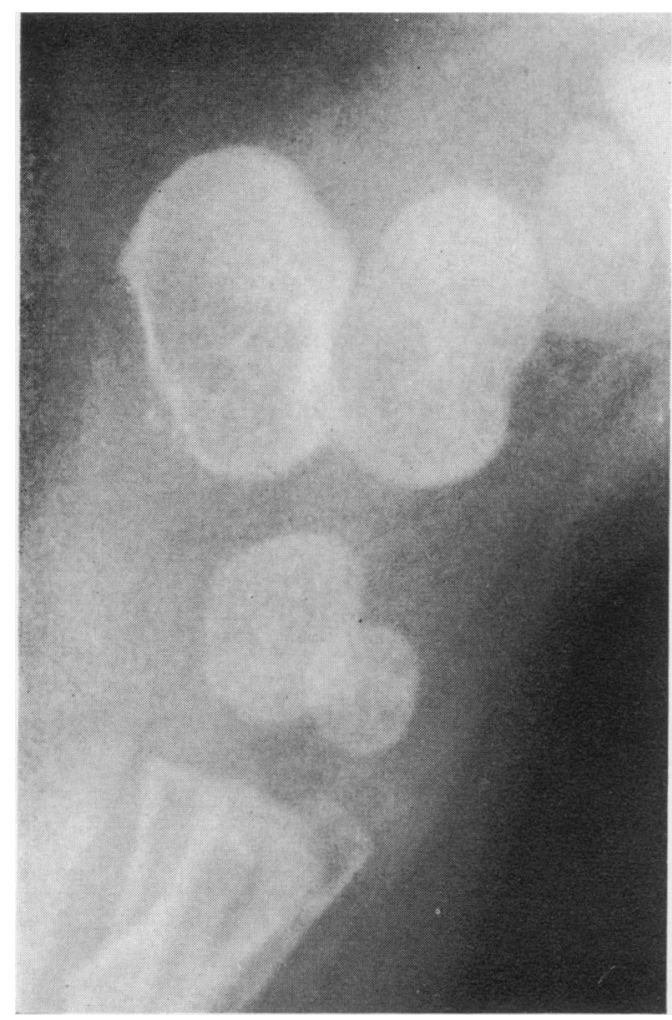

FIG. 5.-Punctuate calcification in left foot almost disappeared.

Family studies and proline loads. Fasting plasma proline levels were determined on the parents, a younger brother, paternal grandparents, an aunt, uncle, and 3 cousins. These were within the normal range $(1.5$ $6.2 \mathrm{mg} / 100 \mathrm{ml}$ ) with the exception of the father and younger brother. In the father on one occasion a value of $8 \mathrm{mg} / 100 \mathrm{ml}$ was found, but on two other occasions normal values were obtained. The younger brother gave the following results which are consistent with the heterozygote state: $10 \mathrm{mg} / 100 \mathrm{ml}$ at 2 weeks, 12 at 4 weeks, 9 at 6 weeks, 7 at 12 weeks, 9 at 5 months, and 6 at 18 months; a mild tyrosinaemia $(7 \mathrm{mg} / 100 \mathrm{ml})$ was observed during the first six weeks of life.

Proline loads were performed on the patient when he was receiving a restricted proline intake, and on his
TABLE II

Proline-free Amino Acid Mixture

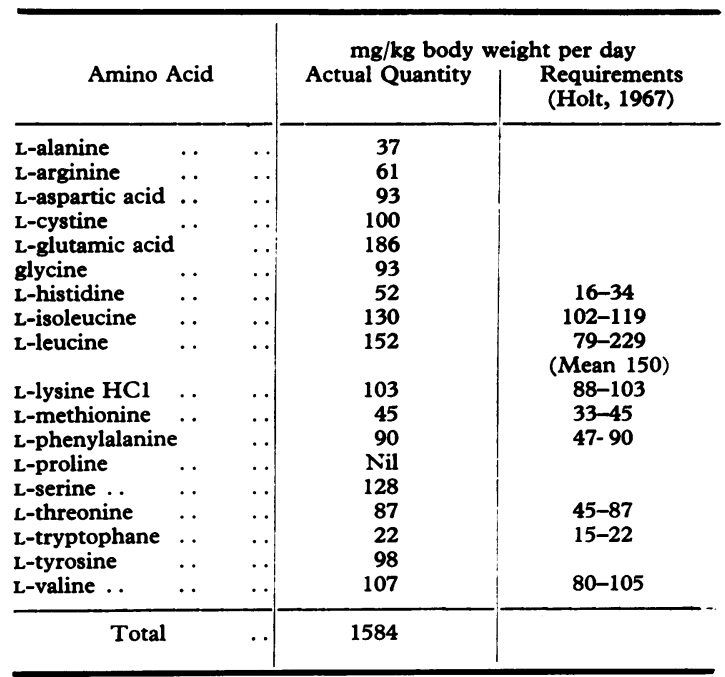

parents and five normal subjects (Fig. 6). The scatter among the normal subjects was greater than that observed by Stănescu et al. (1968) in five normal children. In view of the limited data on normal adult subjects, the results should be interpreted with caution. With this reservation, the response to oral proline loads in both parents, presumed heterozygotes, suggests an impaired ability to handle proline. Under the conditions of this test, the patient's response did not differ from those of his parents.

\section{Discussion}

Proline has been regarded as a non-essential amino acid that can be synthesized from endogenous sources in amounts sufficient for body requirements (Rose et al., 1955). It might therefore be anticipated that in hyperprolinaemia restriction of dietary proline would not result in a marked lowering of the raised plasma levels, because endogenous synthesis of the amino acid would continue or might even increase. The fact that in our patient dietary restriction resulted in a rapid fall of plasma proline levels to normal suggests that endogenous synthesis was not an important source of circulating proline.

The appearance of a rash 4 weeks after starting the diet virtually devoid of proline and its disappearance when additional proline was given, raises the possibility that endogenous proline synthesis was not sufficient to maintain requirements. On the other hand, the fact that it took four weeks of this diet before the rash appeared, and that during this period normal plasma proline levels were maintained and the infant gained weight, make it likely that 


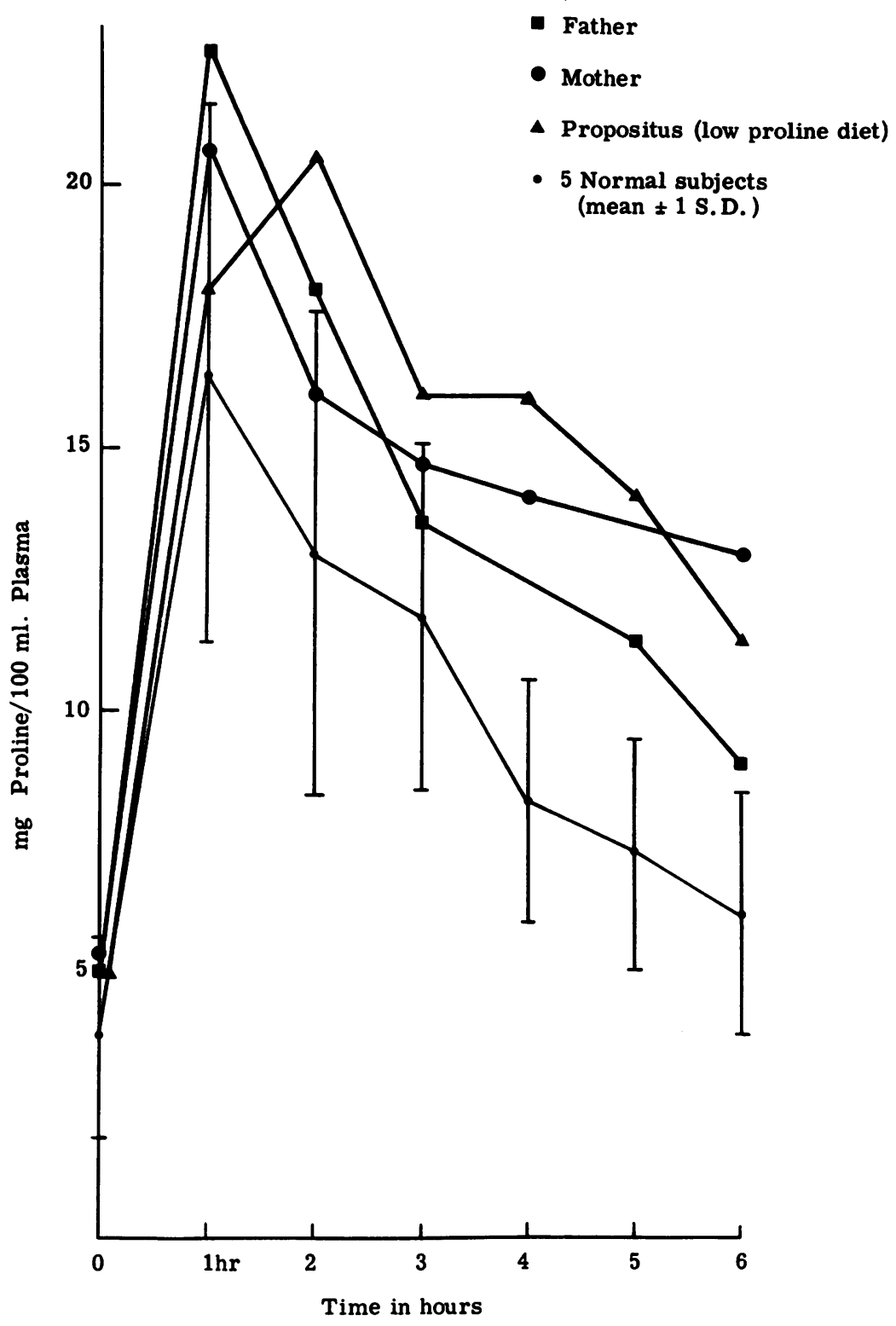

Fig. 6.-Proline load tests.

some endogenous proline synthesis did occur. The enzymic block in proline degradation would also play a part in the maintenance of normal plasma proline levels during the period of severe dietary proline restriction. In our patient, proline might thus be regarded as 'semi-essential'. Though it is not justifiable to draw conclusions from our patient to the normal infant, it is suggested that the evidence that proline is a non-essential amino acid requires re-examination, particularly as far as the period of growth is concerned.

In agreement with our observations is the finding of Jürgens and Dolif (1968) that in parenteral nutrition in man nitrogen retention improves when proline is added to the amino acid mixture. In young rats, Adkins, Wertz, and Hove (1966) noted 
that the omission of proline from a synthetic amino acid diet, which gave a good growth rate, significantly lowered the rate of weight gain.

A similar response to that observed in our patient was seen in a 4-month-old female infant with Type I hyperprolinaemia and seizures (G. H. Newns, personal communication); in this patient, neurological development, hearing, and renal function were normal, but the electroencephalogram showed a slightly abnormal response to photic stimulation. On a normal intake of proline ( $300 \mathrm{mg} / \mathrm{kg}$ per day) plasma levels of proline varied between 10 and $15 \mathrm{mg} / 100 \mathrm{ml}$., and the urinary excretion of proline, hydroxyproline, and glycine was increased; urinary $\Delta^{\prime}$-pyrroline-5-carboxylic acid was not detected. The dietary intake of proline was reduced to $1.4 \mathrm{mg} / \mathrm{kg}$ per day by means of a similar diet to that used in our patient. Twentyfour hours later plasma proline had fallen to $5 \mathrm{mg}$ / $100 \mathrm{ml}$ and remained between 4 and $5 \mathrm{mg} / 100 \mathrm{ml}$ throughout the 7-day dietary period. On reinstitution of a normal diet, plasma proline levels immediately rose again to the previous high levels.

Recently, Goyer, Mitchell, and Leonard (1969) reported a 13-year-old girl with a geneticallydetermined syndrome consisting of renal disease, hearing loss, prolinuria, and ichthyosis. The levels of plasma proline were about twice normal and, after introduction of a low protein and low proline diet, returned to normal. The fall in plasma proline coincided with a fall in blood urea but, since dietary protein and proline were simultaneously reduced, it is not possible to conclude that the fall in plasma proline resulted from the reduction in dietary proline; decreased synthesis of proline from urea and related compounds might also have contributed to the fall.

Efron (1965) reported that, in one patient with Type I hyperprolinaemia, activity of the enzyme proline oxidase in postmortem liver was present though reduced. Table III shows the recovery of urinary proline and hydroxyproline in our patient and in other reported patients with Type I hyperprolinaemia, expressed as percentage recovery of the dietary intake of proline. In making these calculations no allowance has been made of faecal losses of protein and proline, of endogenous synthesis of proline, nor of the conversion of proline to the hydroxyproline of collagen with its subsequent degradation (Efron, Bixby, and Pryles, 1965). It was assumed that the adult patient of Efron (1965) was receiving $1 \mathrm{~g}$ protein $/ \mathrm{kg}$ per day and that proline constituted $5 \%$ of protein. In the 3 patients of Schafer, Scriver, and Efron (1962) dietary intake of protein was assumed to equal urinary nitrogen (i.e. $625 \mathrm{~g}$ dietary protein is equivalent to $100 \mathrm{~g}$ urinary nitrogen). In all the patients the percentage recovery was small, suggesting that the metabolic block in the conversion of proline to $\Delta^{\prime}$-pyrroline-5carboxylate is incomplete, as reported by Efron (1965), and that alternative as yet unknown pathways of proline catabolism exist. In this respect Type I hyperprolinaemia differs from classical phenylketonuria where the metabolic block is almost complete, and $95 \%$ of ingested phenylalanine can be recovered from the urine as phenylalanine or as its metabolites (Armstrong, 1963). Rather the situation in hyperprolinaemia resembles that in hyperphenylalaninaemia in which there is some residual phenylalanine hydroxylase activity (Auerbach, DiGeorge, and Carpenter, 1967) or homocystinuria in which the block is almost complete, but metabolism of methionine to inorganic sulphate occurs by alternative unknown pathways (Brenton et al., 1966; Laster et al., 1965).

Steatorrhoea has not previously been described in hyperprolinaemia, and its pathogenesis remains unexplained in our patient.

Though these studies do not allow us to conclude that dietary treatment helped our patient, we can

TABLE III

Urinary Excretion of Proline and Hydroxyproline Compared with Dietary Intake in Patients with Type I Hyperprolinaemia

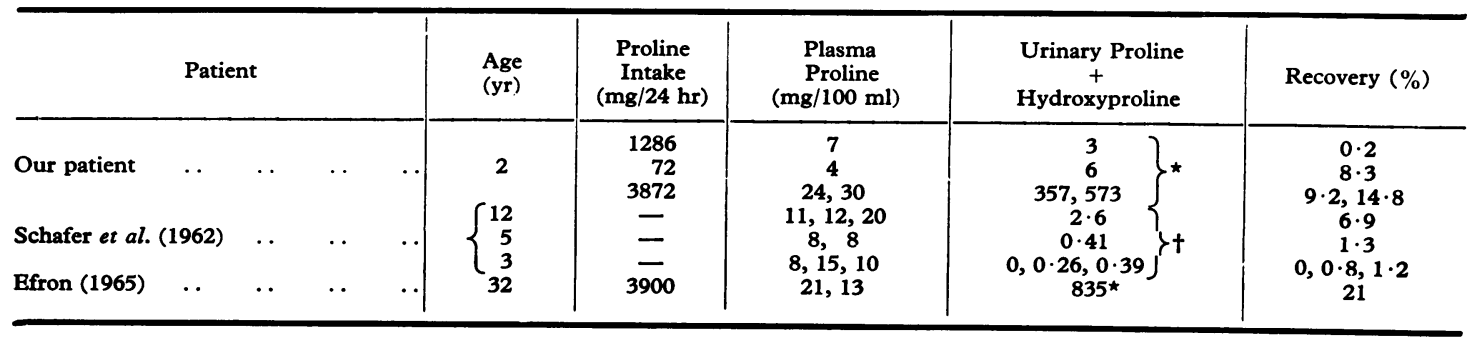

$\star^{*} \mathrm{mg} / 24 \mathrm{hr}$

$\mathrm{tg} / 100 \mathrm{~g}$ total nitrogen. See text for details of these calculations. 
report that the diet was acceptable to the patient and allowed adequate growth to take place. There is a suggestion that during dietary treatment mental development advanced and the skull circumference increased at a greater rate than previously. It is not possible to say whether the diet was responsible for the improvement in the renal and skeletal abnormalities in our patient.

The relation between the metabolic defects and the clinical abnormalities in Type I and Type II hyperprolinaemia is uncertain. The renal abnormalities are probably not the result of the hyperprolinaemia (Efron, 1967) because increase of proline is greater in Type II hyperprolinaemia in which condition renal lesions do not occur, and because the renal disease is inherited from generation to generation as an autosomal dominant condition, whereas the hyperprolinaemia occurs only in sibs of one generation, being inherited as a recessive trait. The relation between the biochemical defect and the neurological abnormalities is also not clear, but genetically the two appear more closely linked, and further trials of dietary treatment therefore seem indicated.

We are grateful to Dr. Graham Fagg for referring the patient and to Dr. George H. Newns for permission to publish details of his patient. We thank Dr. Barbara Clayton for her help and advice, and we appreciate the patience and skill of Sister S. Hensman and her nursing staff. J.W.T.S. also thanks the Nuffield Foundation and the Joint Research Board of The Hospital for Sick Children and the Institute of Child Health for financial support.

\section{APPENDIX I \\ Details of Diet}

Initially the dietary intake of proline was reduced to $1.4 \mathrm{mg} / \mathrm{kg}$ per day by the use of a synthetic diet of L-amino acids, carbohydrate, fat, vitamins, and minerals. The amino acids were administered so as to meet the requirements of all essential amino acids for infants (Holt, 1967).

Supplementary nitrogen was given as non-essential amino acids in a similar proportion to that used in our experience with other dietary regimens for amino acid disorders. The intake of essential amino acids was monitored by frequent blood estimations. The final composition of this proline-free amino acid mixture is shown in Table II. $1.584 \mathrm{~g}$ of this mixture was given per $\mathrm{kg}$ body weight per day, and provided $90 \%$ of the total dietary nitrogen. A caloric intake of $125 / \mathrm{kg}$ per day was maintained by giving glucose, sucrose, synthetic flavourings, and prosparol, $\star$ mixed with the proline-free amino acid mixture and fed by cup and spoon. Fluid

^British Drug Houses: an oil emulsion supplying $4 \cdot 5$ calories per $\mathrm{ml}$. requirements were met by fruit juices. Aminex biscuits $\nmid$ were crushed and used as a cereal, and a small quantity of low protein fruit purée was given as the only other solid. A mineral supplement as described by Westall (1963) was given with this synthetic diet; $4.1 \mathrm{~g}$ salt A $\ddagger$ and $0.35 \mathrm{~g}$ salt $\mathrm{B}$ were given daily mixed with the amino acid mixture providing $379 \mathrm{mg}$ calcium, $8.6 \mathrm{mEq}$ sodium, $25.3 \mathrm{mEq}$ potassium, as well as magnesium, phosphorus, iron, and trace elements. Vitamin supplements were given as Ketovite§ liquid and tablets.

On this dietary regimen, weight gain was satisfactory, but because a rash developed, the intake of synthetic proline was increased as described. This diet was continued until the age of 15 months when the synthetic proline was exchanged for measured quantities of natural foods of known proline content (Table IV). The amino acid mixture was decreased to $0.8 \mathrm{~g} / \mathrm{kg}$ per day, as the natural protein foods now provided $1.8 \mathrm{~g}$ protein $/ \mathrm{kg}$ per day. The synthetic amino acid mixture now provided $30 \%$ of the total nitrogen intake; administration of the supplementary vitamins and minerals was continued. At this stage the total calorie intake was $100 / \mathrm{kg}$ per day and the diet consisted mainly of natural foods.

\section{TABLE IV}

\section{Protein and Proline Content of Natural Foods}

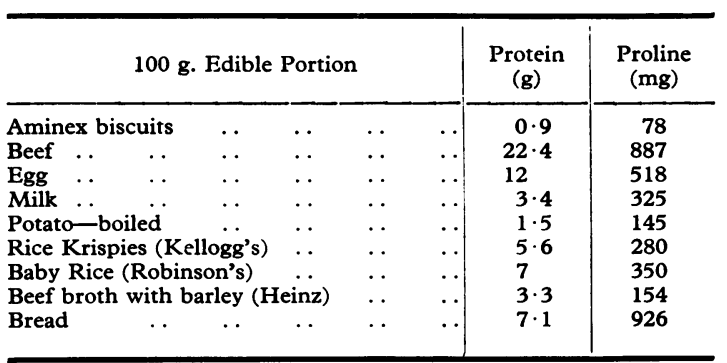

Rejected foods were replaced by an equivalent amount of proline as milk. A sample diet used at $\mathbf{1 5}$ months is shown in Table V. Proline intake was adjusted so as to keep plasma levels between 8 and $10 \mathrm{mg} / 100 \mathrm{ml}$; only minor adjustments were necessary, the proline intake varying between 100 and $125 \mathrm{mg} / \mathrm{kg}$ per day. The total protein intake, composed of natural proteins and synthetic amino acids varied between $2 \cdot 0$ and $2 \cdot 7 \mathrm{~g} / \mathrm{kg}$ per day.

Proline intake in normal infants. We have calculated the 'normal intake' of proline to be that amount contained in a normal diet providing protein requirements of $3 \mathrm{~g} / \mathrm{kg}$ per day at the ages of 4 weeks and 1 year using the data of McCance and Widdowson (1960). A 4-week-old infant receiving human milk would receive

†Aminex biscuits (Liga): each biscuit contains 50 calories, $10.9 \mathrm{mg}$ proline, and $0.14 \mathrm{~g}$ protein.

‡'Maple Syrup Mineral Mixture’ (Scientific Hospital Supplies) replaced Salt $A$ when it became commercially available.

§Paines and Byrne. 


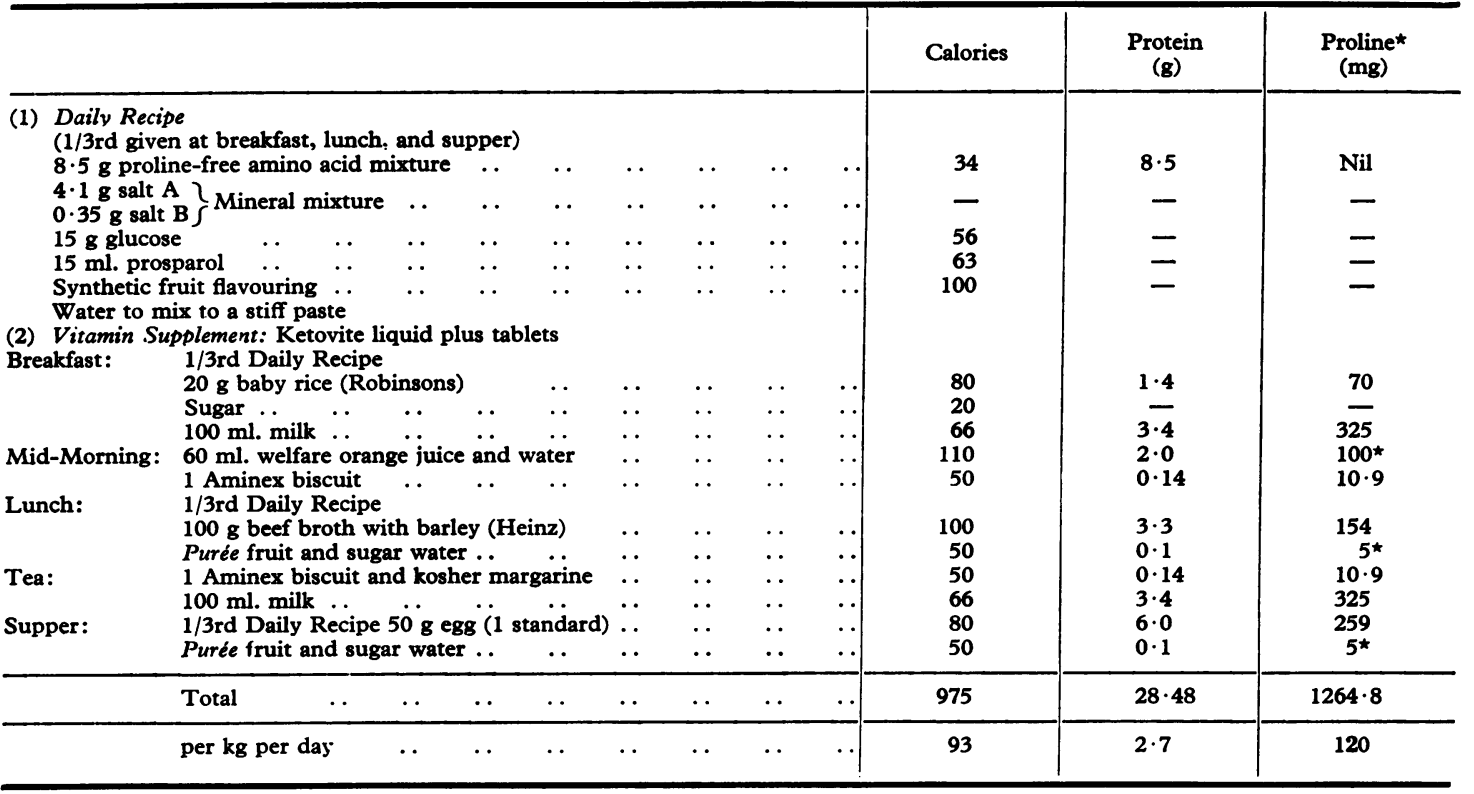

$\star$ Calculation based on protein containing approximately $5 \%$ proline.

$250 \mathrm{mg}$ proline/kg per day and on fresh whole cow's milk this would be $290 \mathrm{mg} / \mathrm{kg}$ per day. Table VI shows the proline content of a normal diet for an infant of 1 year.

\section{TABLE VI}

Proline Content of Normal Diet at 1 year

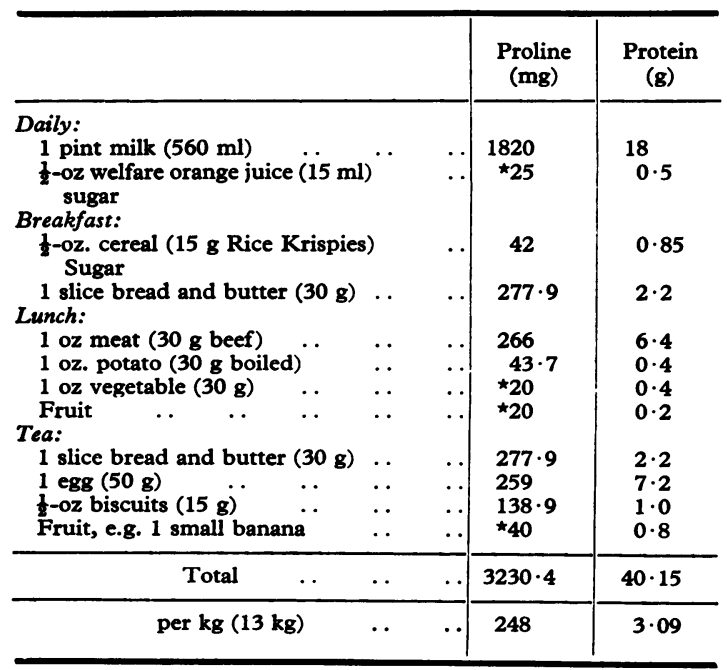

*Calculation based on protein containing approximately $5 \%$ proline.
These figures indicate that dietary intake of proline during the first year of life would normally amount to at least $250-300 \mathrm{mg} / \mathrm{kg}$ per day. It should be noted that in this country, many infants consume more than $3 \mathrm{~g}$ protein/kg per day.

\section{APPENDIX II (R. S. Ersser) \\ Determination of Proline by Chinard's Reaction (1952)}

The amino acids were isolated from plasma $(0.2 \mathrm{ml})$ and urine $(0.4 \mathrm{ml})$ by absorption on a column $1 \times 5 \mathrm{~cm})$ of an ion-exchange resin (ZeoKarb 225, SRC10, $\mathrm{H}+$ ). The resin was washed thoroughly with water, and proline, together with other neutral and acidic amino acids and some histidine, was eluted with $1.25 \mathrm{M}$ pyridine $(25 \mathrm{ml})$. The eluate was taken to dryness in a rotary evaporator $\left(50^{\circ} \mathrm{C}\right)$, and the residue dissolved in water $(4 \mathrm{ml})$. Duplicate portions $(1 \mathrm{ml})$ of the prepared extract were heated in a boiling water bath with Chinard's reagent $(2 \mathrm{ml})$ for 1 hour. This reagent is a solution of ninhydrin $(0.3 \mathrm{~g})$ in glacial acetic acid $(24 \mathrm{ml})$ containing syrupy phosphoric acid $(90 \%, 4 \mathrm{ml})$ and water $(2 \mathrm{ml})$.

Standard solutions containing $2,5,10$, and $20 \mathrm{mg}$ proline $/ 100 \mathrm{ml}$ were treated in the same way together with a reagent blank, substituting deionized water $(1 \mathrm{ml})$ for the sample solution. The tubes were cooled in cold water $(5 \mathrm{~min})$ shaken with benzene $(1 \mathrm{ml})$ in a vortex mixer ( $2 \times 15$ seconds), and centrifuged. The optical 
density of the benzene layer was read, against benzene, in a spectrophotometer at a wavelength of $515 \mathrm{~m} \mu$, using $10 \mathrm{~mm}$ microcells. The red colour was stable for at least $30 \mathrm{~min}$ and no special precautions were found necessary to correct for benzene evaporation during reading.

In the concentration range $2-30 \mathrm{mg} / 100 \mathrm{ml}$, Beer's law was obeyed. The recovery in the range 5-20 mg proline $/ 100 \mathrm{ml}$ was $96 \cdot 2 \pm 2 \cdot 4 \%( \pm 1 \mathrm{SD})$ and for standards added to plasma $94 \cdot 7 \pm 1 \%$.

Ornithine and 21 amino acids derived from natural protein were taken through the procedure and only the following gave a colour (O.D. of proline reference $100 \%)$ : ornithine $(65 \%)$, lysine $(11 \%)$, hydroxylysine $(3 \%)$, hydroxyproline $(6 \cdot 5 \%)$, cysteine $(35 \%)$ but not cystine. With the exception of hydroxyproline, the interfering amino acids were eliminated by the column procedure. Using this method we found plasma proline concentrations and urinary proline excretion in normal individuals to be as follows:

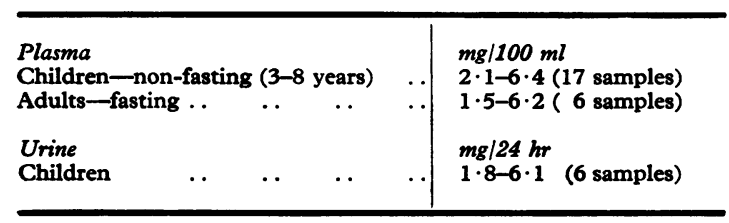

\section{REFERENCES}

Adkins, J. S., Wertz, J. M., and Hove, L. E. (1966). Influence of nonessential $L$-amino acids on growth of rats fed high levels of essential L-amino acids. Proceedings of the Society for Experimental Biology and Medicine, 122, 519.

Armstrong, M. D. (1963). Biochemistry. In Phenylketonuria, p. 62. Ed. by F. L. Lyman. C. C. Thomas, Springfield, Illinois.

Auerbach, V., DiGeorge, A. M., and Carpenter. G. G. (1967) Phenylalaninaemia. In Amino Acid Metabolism and Genetic Variation, p. 11. Ed. by W. L. Nyham. McGraw-Hill, New York.

Brenton, D. P., Cusworth, D. C., Dent, C. E., and Jones, E. E. (1966). Homocystinuria. Clinical and dietary studies. Quarterly fournal of Medicine, 35, 325.
Chinard, F. P. (1952). Photometric estimation of proline and ornithine. Fournal of Biological Chemistry, 199, 91.

Efron, M. L. (1965). Familial hyperprolinaemia. Report of a second case, associated with congenital renal malformations, hereditary hematuria, and mild mental retardation, with demonstration of an enzyme defect. Ner England fournal of Medicine, 272, 1243.

Bfron, M. L. (1967). Treatment of hydroxyprolinemia and hyperprolinemia. American fournal of Diseases of Children, 113, 166.

Efron, M. L., Bixby, E. M., and Pryles, C. V. (1965). Hydroxyprolinemia. II. A rare metabolic disease due to a deficiency of the enzyme 'hydroxyproline oxidase.' New England fournal of Medicine, 272, 1299.

Goyer, R. A., Mitchell, B. J., and Leonard, D. L. (1969). Dietary reduction of hyperprolinemia. Fournal of Laboratory and Clinical Medicine, 73, 819.

Holt, L. E., Jr. (1967). Amino acid requirements of infants. Current Therapeutic Research, 8, 149.

Jürgens, P., and Dolif, D. (1968). Die Bedeutung nichtessentieller Aminosăuren für den Stickstoffhaushalt des Menschen unter parenteraler Ernăhrung. Klinische Wochenschrift, 46, 131.

Laster, L., Mudd, S. H., Finkelstein, J. D., and Irreverre, F. (1965). Homocystinuria due to cystathionine synthase deficiency: the metabolism of L-methionine. Fournal of Clinical Investigation, 44, 1708.

McCance, R. A., and Widdowson, E. M. (1960). The composition of foods. Medical Research Council Special Report Series, 297.

Meister, A. (1965). Proline. In Biochemistry of Amino Acids, Vol. II, p. 707. Academic Press, New York.

Piesowicz, A. T. (1968). Hyperprolinaemia. Archives of Disease in Childhood, 43, 748.

Rose, W. C., Wixom, R. L., Lockhart, H. B. and Lambert, G. F. (1955). The amino acid requirements of man. XV. The valine requirement: summary and final observations. fournal of Biological Chemistry, 217, 987.

Schafer, I. A., Scriver, C. R., and Efron, M. L. (1962). Familial hyperprolinemia, cerebral dysfunction and renal anomalies occurring in a family with hereditary nephropathy and deafness. New England fournal of Medicine. 267, 51.

Scriver, C. R., Schafer, I. A., and Efron, M. L. (1961). New renal tubular amino-acid transport system and a new hereditary disorder of amino-acid metabolism. Nature, 192, 672.

Stănescu, V., Florea, I., Ionescu, V., Dinulescu, E., and Stănescu, R. (1968). L-proline loading test in growth disturbances. Helvetica Paediatrica Acta, 23, 147.

Westall, R. G. (1963). Dietary treatment of a child with maple syrup urine disease. Archives of Disease in Childhood, 38, 485.

Correspondence to Professor O. H. Wolff, Institute of Child Health, Guilford Street, London W.C.1. 